\title{
Probabilistic risk appraisal and mitigation of critical infrastructures for seismic extreme events
}

\author{
Alon Urlainis, Igal M. Shohet \\ Structural Engineering Department, Ben-Gurion University of the Negev, Beer-Sheva, Israel
}

\begin{abstract}
The importance and the interdependencies of critical infrastructures such as power and water supply, communications, and healthcare is increasing continuously and constantly. Most of the vital services for the private and the public sectors depend on the continuous performance of critical infrastructures. However, the last decades' extreme events reveal a significant gap between the preparedness of critical infrastructures and the actual risk that those infrastructures are exposed to in case of seismic event. In this research a methodology is developed to appraise and mitigate the risk that critical infrastructures are exposed to in case of seismic events. The proposed method is designated also to act as decision support tool for the selection of the most advantageous strategy to reduce the risk expectancy for extreme seismic events.

A Probabilistic Seismic Hazard Analysis (PSHA) approach is used in order to reflect a variety of possible seismic scenarios and overcome the uncertainties regarding to the timing, the location, and the magnitude of an earthquake. The seismic vulnerability of different components is evaluated by adjusted fragility curves and Fault-Tree-Analysis. The seismic risk function, that expresses the expected risk of the system for a given ground motion intensity, is derived according to the occurrence probabilities of the earthquake, the seismic vulnerability of different components, and the expected consequences.

This paper introduces the developed methodology and demonstrates the key steps through a two case studies of oil pumping plant and oil tank farm. The pumping plant case study demonstrates the development of the risk function and examines the contribution of a possible mitigation strategy on the overall risk expectancy. The oil tank farm case demonstrates a derivation of an exclusive fragility function for critical infrastructures facility.

This methodology provides novel analytical and decision-support tool that integrates between the components adjusted fragility curves in the risk assessment and the consequent mitigation step; the optimal mitigation strategy is derived from the fragility parameters reflection on the total risk function.
\end{abstract}

(C) 2018 The Authors. Published by Diamond Congress Ltd., Budapest University of Technology and Economics Peer-review under responsibility of the scientific committee of the Creative Construction Conference 2018.

Keyword : Critical infrastructure; Risk appraisal; Risk Mitigation; Fragility curve; Earthquakes;

\section{INTRODUCTION}

Critical Infrastructures (CI) play a crucial role in the normal performance of the economy and society. Over the last decades the amount and the variety of critical infrastructures grew rapidly, and the interdependency between them increased constantly; consequently, more and more essential services depend on the continuous performance of one, two or even more critical infrastructures such as power, water supply, communications, etc.

As was observed in previous studies, there is a significant gap between the stability and the preparedness level of CIs for seismic events and the actual damage that those facilities are exposed to in a case of a seismic event [1]-[3]. The consequences of the latest seismic events emphasize the importance to mitigate the seismic risk by increasing the preparedness of CIs and ensuring reliable and robust performance on a continuous basis, particularly during and after 
the occurrence of extreme events. Implemented mitigation strategy is derived accordingly to the financial limitation and depends on decision makers' policy. Therefore, at first, in order to clarify the actual risk that CIs are exposed to in case of seismic event the risk should be quantified. Subsequently, in case the risk is not acceptable, different mitigation strategies must be examined in order to select the most optimal strategy, respectively to the financial feasibility.

The major objective of this research is to develop a probabilistic methodology that examines the preparedness of critical infrastructures through an appraisal of the risk that CIs are exposed in case of seismic events and provide a decision support tool for risk mitigation. Prior methodologies for risk appraisal [4]-[6] presented procedures that offer tools such as fragility curves, fault tree analysis, logic tree in order to appraise the risk of different components. Those methodologies presented tools to appraise the risk for existing generic infrastructures based on empiric data. However, those studies didn't examine different mitigation strategies and their effectiveness on the risk reduction and didn't conclude to the optimal strategy. Moreover, those methodologies are mainly used in order to appraise the risk as a result of a specific earthquake event.

This methodology is intended to expand prior risk appraisal tools such as fragility curve and fault tree analysis and implement them as a decision support tool for policy makers. This methodology intended to quantify the seismic risk by a probabilistic seismic analysis of a variety of possible seismic scenarios and examine different mitigation strategies in order to conclude the most optimal mitigation strategy under the given financial constraints.

\section{Methodology}

\subsection{Seismic Hazards Identification}

The seismic threat for each CI's component is identified according to the location of the facility according probabilistic seismic hazard analysis (PSHA) as presented by [7]. The PSHA approach is intended to consider all possible scenarios according to geological data about the possible earthquake sources, and the probability of magnitude and intensity occurrence that is associated with those events. The PSHA approach requires ground-motion attenuation models that estimate the expected ground-motions at a given site as a result of different intensity and location earthquakes, several studies offer attenuation models for different location and regions [8], [9]. This step yields an Annual Rate of Exceedance curve $\left(P E_{A}\right)$ as a function of a given ground motion intensity measure (IM); when in most cases, for above-ground structures the IM is expressed in term of peak ground acceleration (PGA) [10]-[12].

\subsection{System’s Seismic Vulnerability}

In this step, the expected damage state as a result of a seismic event is formulated in terms of fragility curve. The fragility curve expresses the probability of reaching or exceeding certain damage states for a given level of IM [13][16]. This function is fully defined by determination of two parameters: median capacity of the component to resist the damage state $(\theta)$ and standard deviation of the capacity $(\beta)$.

$$
P[D S \geq d s \mid I M=x]=\Phi\left(\frac{\ln \left(x / \theta_{d s}\right)}{\beta_{d s}}\right) ; d s \in\left\{1,2, \ldots N_{D}\right\}
$$

Eq. 1 expresses a formulation of a fragility function. When $P$ stands for a conditional probability of being at or exceeding a particular Damage State $(D S)$ for a given seismic intensity $x$ defined by the earthquake Intensity Measure (IM).

Where,

$D S \quad$ Uncertain damage state of a particular component. $\{0,1, \ldots \mathrm{Nn}\}$

$d s \quad$ A particular value of DS

$N_{D} \quad$ Number of possible damage states

IM Uncertain excitation, the ground motion intensity measure (i.e. PGA, PGD, or PGV)

$x \quad$ A particular value of IM

$\Phi \quad$ Standard cumulative normal distribution function.

$\theta_{d s} \quad$ The median capacity of the component to resist damage state ds measured in terms of IM 
$\beta_{d s} \quad$ Logarithmic standard deviation of the uncertain capacity of the component to resist damage state ds

In this step, the fragility parameters can be yield on the existing values that are available for generic components based on prior studies [4], [6], [12], [17]. However, in the case of a unique system or component, it is preferable to develop exclusive values for the system in accordance to the fragility of the sub-component.

\title{
2.3 Damage Assessment due to seismic Extreme Events for different components
}

This step associates a damage ratio $\left(D R_{i}\right)$ with each damage state; the $D R_{i}$ expresses the percentage of the total replacement value of a component corresponding to damage state $i$. Subsequently, since the damage ratio is associated directly to the damage state, the expectant damage ratio of a component $\left(D R_{c}\right)$ can be calculated as follows:

$$
D R_{c}=\sum_{d s} D R_{i} * P\left(d s_{i} \mid I M\right)
$$

\author{
Where \\ $\mathrm{DR}_{\mathrm{i}} \quad$ Damage rate of the damage state $\mathrm{i}$ \\ $\mathrm{P}\left(\mathrm{ds}_{\mathrm{i}} \mid \mathrm{IM}\right) \quad$ Conditional probability of being in a certain damage state $\mathrm{i}$ for a given IM
}

Furthermore, the expected repair $\operatorname{cost}\left(R C_{c}\right)$ of the component for a given IM can be calculated regarding to the replacement value $\left(R V_{c}\right)$; when the $R V_{c}$ expresses the total replacement cost of the component. Thus, one can calculate the expected direct damage of the component for any given IM as follows:

$$
R C_{c}(I M)=R V_{c} \cdot \sum_{d s} D R_{i} \cdot P\left(d s_{i} \mid I M\right)=D R_{c} * R V_{c}
$$

\subsection{Risk Appraisal according to expected damage}

The product of this step is a seismic risk curve that presents the expected annual risk for any given value of IM. Since risk represents the potential impact and loss and it is defined as the product of the occurrence probability and the expected consequences, this curve is constructed by multiplying the annual rate of exceedance curve with the direct damage curve by matching between the PGA values in both curves and links the expected consequence and its probability to occur. This matching produces a curve that correlated between the expected damage in terms of annual expectancy of risk and the PGA.

$$
R_{A}(I M)=R C_{c}(I M) \cdot P E_{A}(I M)
$$

Where
$\mathrm{R}_{\mathrm{A}}(\mathrm{IM})$
Annual risk for a given IM
$\mathrm{RC}_{\mathrm{c}}(\mathrm{IM})$
Replacement cost of the component for a given IM
$\mathrm{PE}_{\mathrm{A}}(\mathrm{IM})$
Annual rate of exceedance of a given IM

\subsection{Risk Mitigation}

In this step, different mitigation strategies are examined in order to predict the effectiveness of the mitigation strategy on the preparedness level of the CIs by quantifying the reduction of risk followed by implementation of each strategy. Each examined mitigation strategy has different effects on the robustness and the resilience of the system which is reflected in different parameters of the fragility curve; those changes will effect on the level of risk. Subsequently, the optimal strategy is selected according to the level of reduction of risk and economic considerations. 


\section{Methodology implementation: Case study 1}

This chapter demonstrates a conceptual implementation of the methodology through a case study of an oil pumping plant (PP). Pumping plants serve to maintain the flow of oil across pipeline system. They are located at certain intervals along the pipeline network to ensure the transport over long distances and around the storage facilities when the pressure must be increased due to friction losses. In addition, Pumping is also required to transport oil uphill wherever this is required by topographic conditions.

The annual rate of exceedance curve depends on the specific location of the facility. Therefore, in this case, the pumping plant is assumed to be located in Beer-Sheva, Israel. A simplified annual rate of exceedance curve (Figure 1) was derived based on the values that were published by the Geophysical Institute of Israel report [18]. In this report, the attenuation is based on the model of [19] which has a good correlation to the Middle-East seismic patterns. This attenuation model considers a sufficient range of magnitudes (4-8.5) and allows considering the effects of weak seismic areas. Moreover, this attenuation considers main parameters of site effect such as: Magnitude (M), distance from rupture (R), fault mechanism, and soil stiffness.

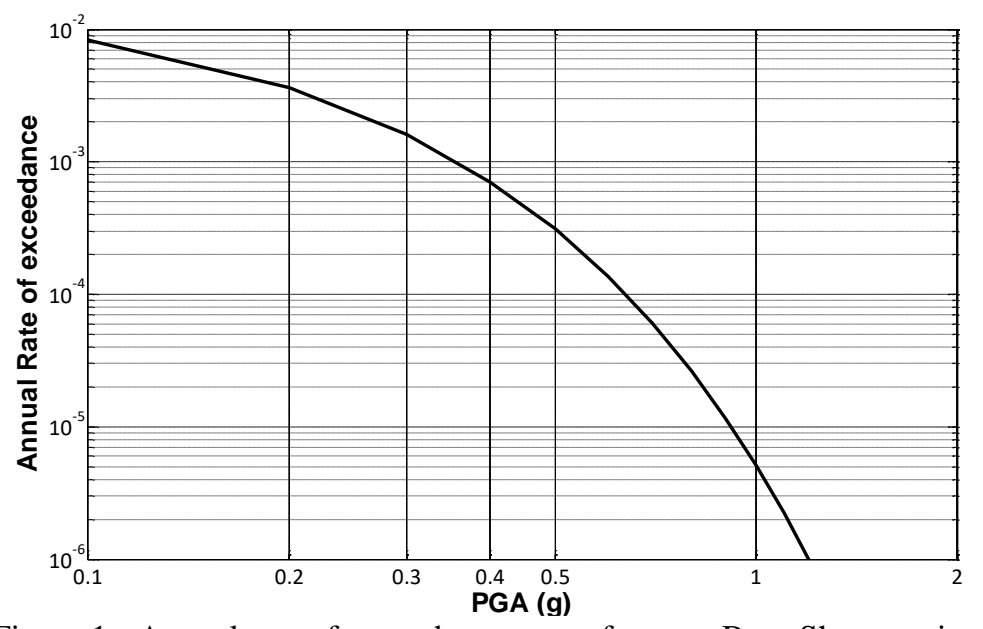

Figure 1 - Annual rate of exceedance curve for west Beer-Sheva region

According to [6] the failure of a pumping plant is most likely to occur as a result of damage to one of its main subcomponents: the building, one or more pumps, electrical equipment, and electric power and backup systems.

In this case, the fragility parameters are based on the values proposed by [4] for unanchored pumping plant (Figure 2), the damage ratio of the tank is based on the estimate damage ratio that proposed by [4], and the replacement cost for a pumping plant is estimated at 1M US\$.

Table 1.Damage states description and parameters of an oil pumping plant and the damage ratio values as proposed by [4]

\begin{tabular}{cllrrr}
\hline Damage state $\left(\boldsymbol{D} \boldsymbol{s}_{\boldsymbol{i}}\right)$ & Damage Description & $\boldsymbol{\theta}$ & $\boldsymbol{\beta}$ & $\boldsymbol{D} \boldsymbol{R}_{\boldsymbol{i}}$ \\
\hline$D s_{1}$ & Slight/minor & Defined by light damage to building & 0.12 & 0.60 & 0.08 \\
$D s_{2}$ & Moderate & $\begin{array}{l}\text { Defined by considerable damage to mechanical and electrical equipment, or } \\
\text { considerable damage to building }\end{array}$ & 0.24 & 0.60 & 0.40 \\
$D s_{3}$ & Extensive & Defined by the building being extensively damaged, or pumps badly damaged. & 0.77 & 0.65 & 0.80 \\
$D s_{4}$ & Complete & Defined by the building being in complete damage state & 1.50 & 0.80 & 1.00 \\
\hline
\end{tabular}

Following the above parameters (Table 1), the risk function is derived by an integration of the annual rate of exceedance curve with the fragility curve, the damage ration $\left(D R_{c}\right)$, and the replacement value $\left(R V_{c}\right)$. The risk curve analysis shows that low-moderate ground accelerations, where the exceeded PGA is lesser than 0.8, have a major contribution to the total annual risk of the pumping station (Figure 3). 


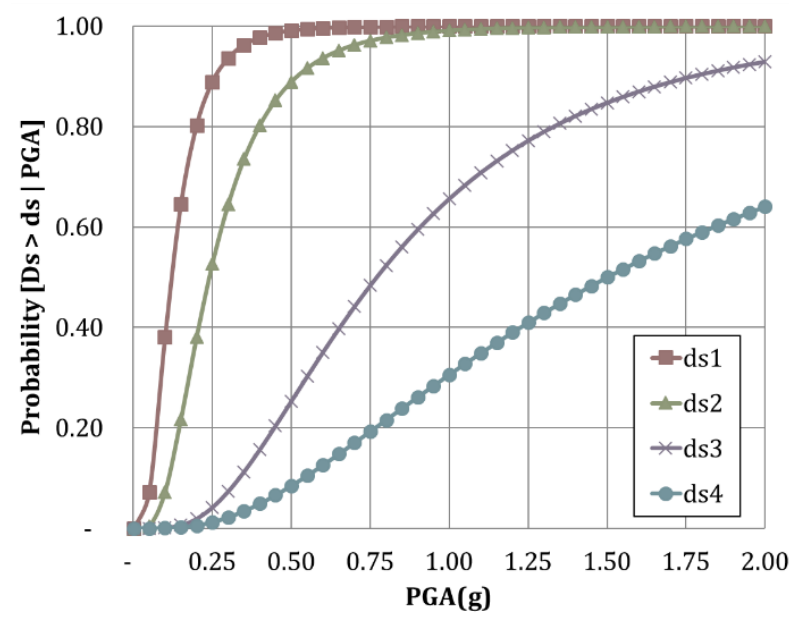

Figure 2 - Fragility curve for pumping plant

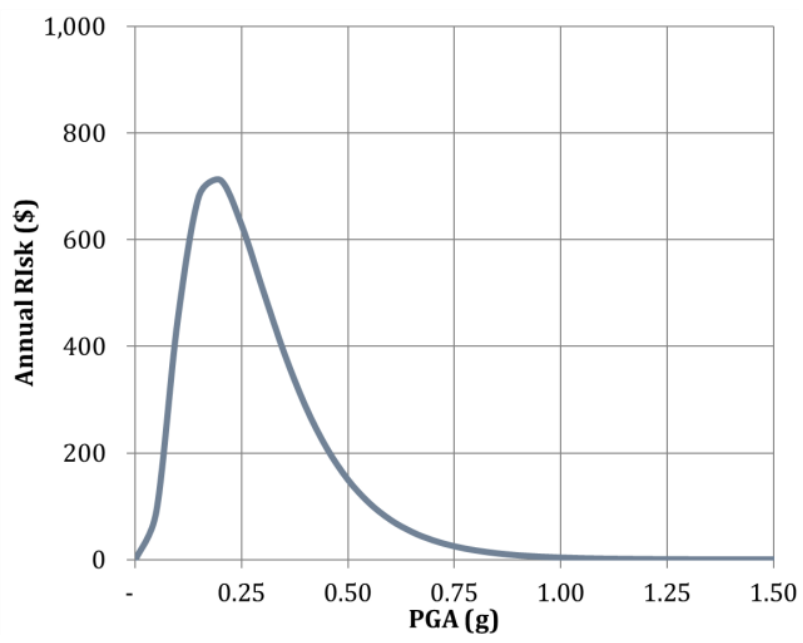

Figure 3 - Risk curve for pumping plant

One of the possible methods to reduce the potential damage of the PP in case of seismic event is anchoring the subcomponents of the station. This strategy is increasing the resistance of the subcomponents to overcome moderate level ground accelerations and subsequently increases the robustness of the pumping plant for seismic events. Implementation of this strategy modifies the fragility curve parameters for $d s_{1}$ and $d s_{2}$, which gives a relatively high probability to exceed this damage states in case of moderate ground for the unanchored plant while anchoring the subcomponents reduces the probabilities to exceed $d s_{1}, d s_{2}$ in case of moderate ground aFUlccelerations (Figure 4). This mitigation strategy reduces the total risk of the pumping plant. The reduction is mainly effect the damage that expected as a result of moderate ground motion. An analysis of the derived risk curves for unanchored and anchored plants shows that anchoring the components can reduce the risk by about 27\% (Figure 5).

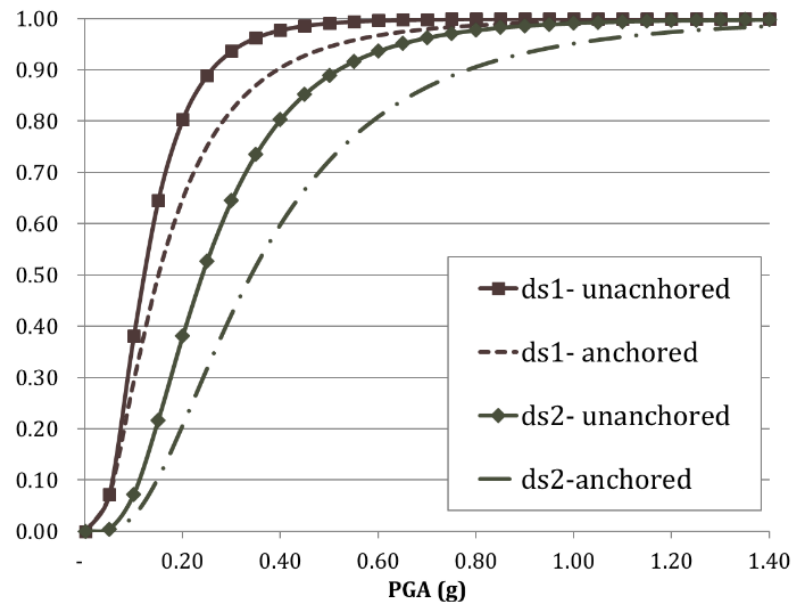

Figure 4 - Comparison of $\mathrm{ds}_{1}$ and $\mathrm{ds}_{2}$ for anchored and unanchored pumping plant

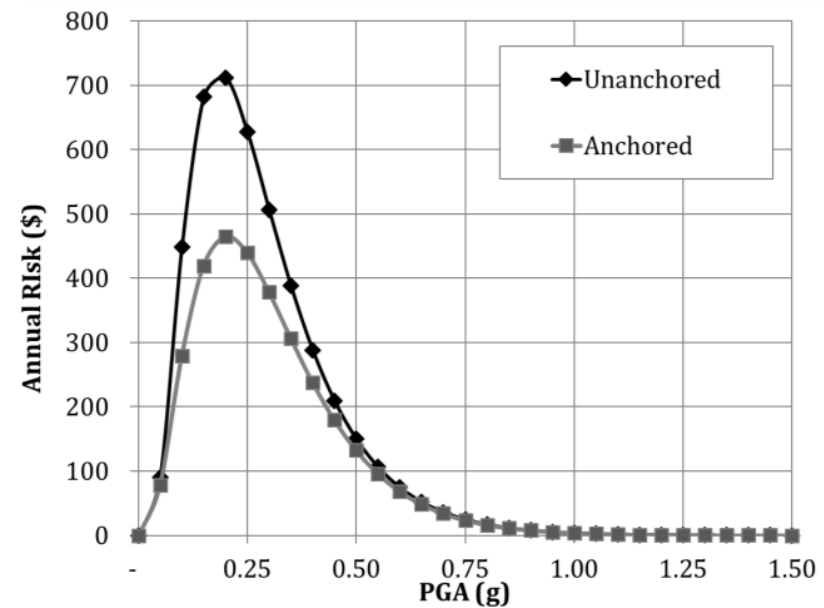

Figure 5 - Comparison of the derived risk curve for anchored and unanchored pumping plant

\section{Seismic vulnerability function: Case study 2}

This chapter demonstrates the derivation of a fragility function for exclusive critical infrastructures facility through a case study of an oil tank farm. In case of an exclusive facility or component of a system, it is desired to derive and use the best fit fragility curve. The main purpose of this step is to produce a unique fragility based on an aggregation of the fragilities of the sub-components (Figure 6). In this example, it is considered that the oil tank farm is composed of five main sub-components: building, storage tanks, power grid, backup generator, and mechanical equipment. 


\subsection{Building}

The control center of the farm is in a low-rise building. The building serves for the control and the supervision on the ongoing operation of the farm. In our case, the building is a one-story RC building. The fragility parameters are based on [6].

\subsection{Tanks}

Oil storage tanks are used for storage of different petroleum products for a long or a brief time; the oil farm consist several storage tanks that. The modern oil storage tanks are varying from $12-76 \mathrm{~m}$ in diameter with heights to diameter ratio (H/D) is mostly lesser than one. The most common design type of tanks is cylindrical ground-supported tank due to their efficient resistance to hydrostatic pressure and can be easily constructed. In addition, most of the oil storage facilities are composed of welded steel with floating roof. Several fragility parameter sets are offered by the literature based on empirical data. The HAZUS procedure provides data for steel tanks categorized the tank only whether it is anchored or unanchored. In addition, [6], [10] suggest considering parameters such as H/D ratio and fill level. In this case, the fragility parameters are based on the values proposed for tank with H/D ratio lesser than 0.7, which are the most compatible for the tanks on the oil farm. Moreover, in case of tank farm, the fragility of the farm will be yield corresponding to damage states definition, and as a binomial distribution of $k$ damaged tank of $n$ total tanks in the farm.

\subsection{Diesel generator}

The diesel generator is used as emergency power-supply in cases the external power grid is fails. The generator is mostly varying by capacity, vibration isolation, and anchoring. In this case, the backup generator is a diesel generator with a Capacity of 350 to $750 \mathrm{kVA}$ with unanchored equipment and without vibration isolation. The fragility parameters are based on [4], [20]

\subsection{Power grid}

The operation of the site is based on the ongoing supply of electric power. In our case, the electric power supply is based on two sources: In routine, the electric power supply to the facility is based on the local electricity distribution networks. in case, of a malfunction or damage to the external electrical path, a generator is placed in the facility to provide a solution until the electricity supply is restored. For this case study, the fragility parameters of the power grid are based on HAZUS methodology [4].

\subsection{Mechanical equipment}

For this case study, the fragility parameters for the mechanical equipment are based on HAZUS methodology [4]. 


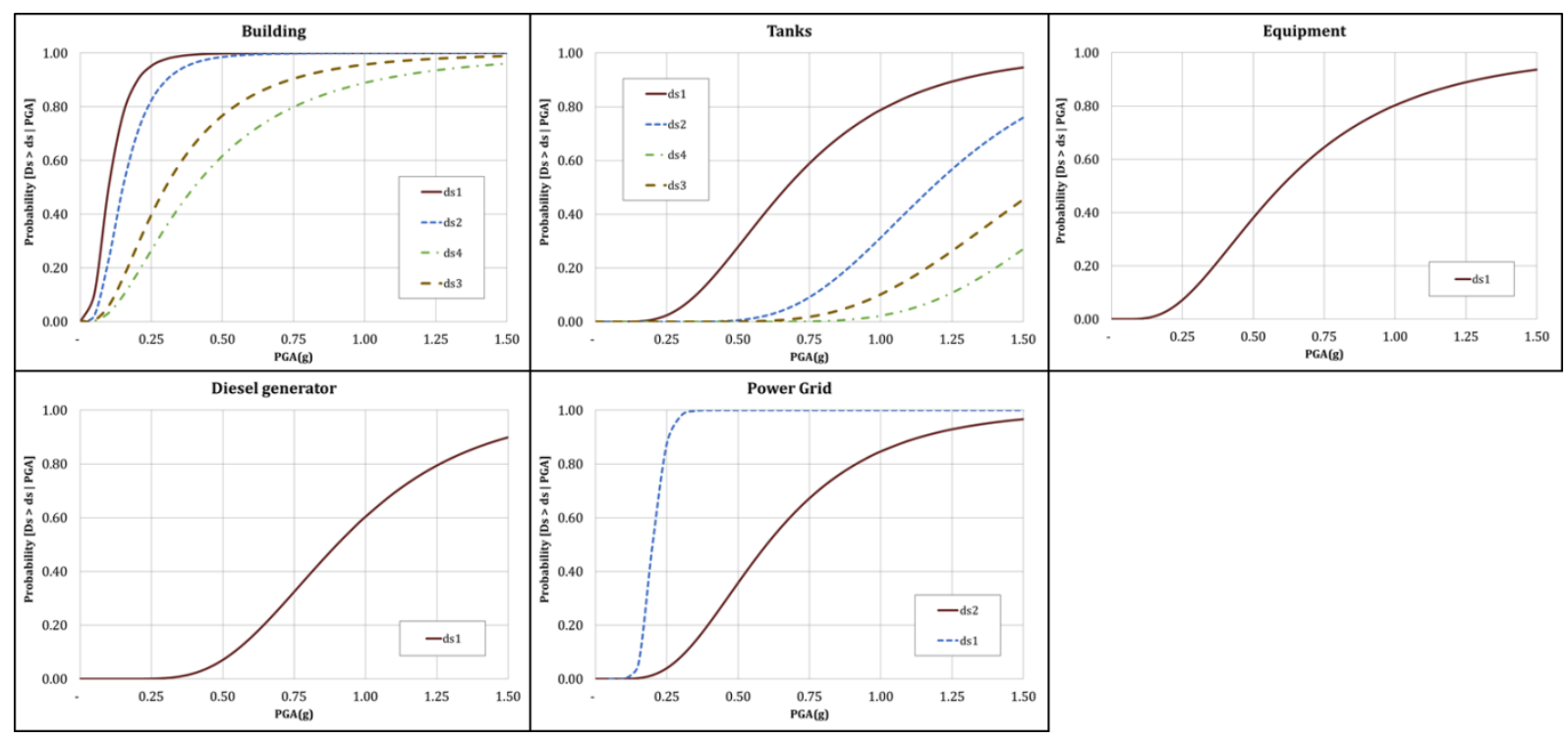

Figure 6 - Fragility curves of the system's sub-components

\subsection{Development of the system fragility curve}

Based on the fragility parameters of the sub-components and the system damage state definition one can develop a unique fragility curve for a specific system, which in our case, an oil tank farm. The composed fragility curve is composed of several curves that express the sequential damage states of the system. At the last step of the fragility development is the evaluation of the fragility parameters of each damage state $\left(\theta_{d s}\right.$ and $\left.\beta_{d s}\right)$. This procedure can be implemented by Excel solver for each damage state. Figure 7 below presents the fragility curves of the oil tank farm based on those parameters.

\section{Oil Tank Farm}

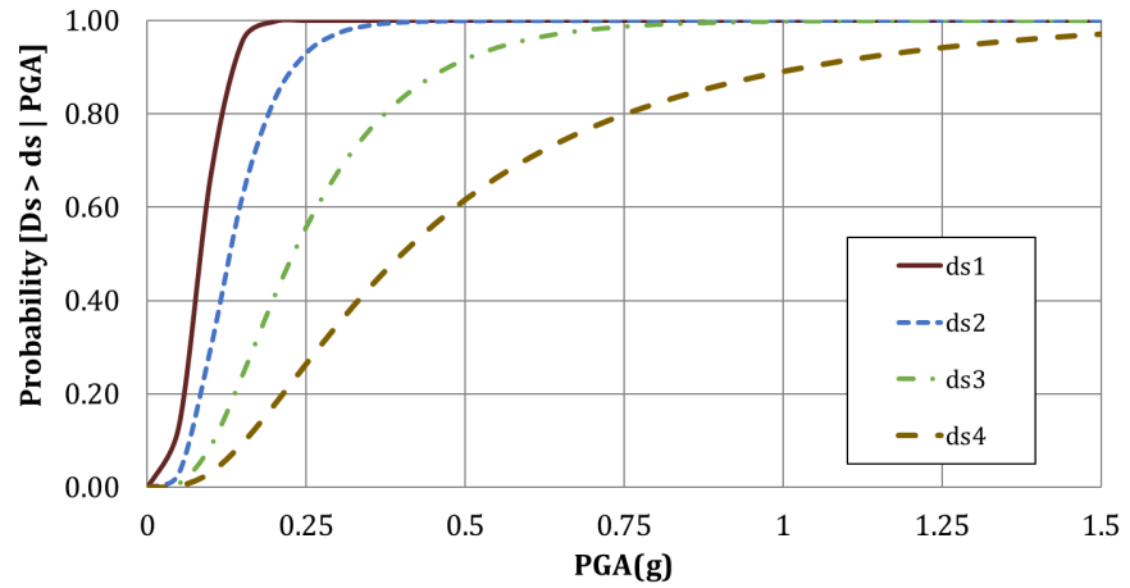

Figure 7 - Fragility curve of the oil farm

\subsection{Comparison with the literature}

A comparison of our results with fragility parameters that are proposed by [4] are presented in Table 2. The differences between the parameters are most likely due to the differences in the definition of the events that attributed to each damage state. It is required to perform further analysis to examine the sensitivity of the scenarios that are defined to each damage state and to associate the scenarios with the changes in the fragility curves. 
Table 2 - Comparison of this paper results with fragility parameters that are proposed by (NIBS 2004)

\begin{tabular}{cccccc}
\hline Damage State & \multicolumn{2}{c}{ This research } & \multicolumn{2}{c}{ NIBS 2004 [4] } & $\beta$ \\
\hline Slight/minor & $\theta$ & $\beta$ & 0.12 & 0.55 \\
Moderate & 0.10 & 0.52 & 0.23 & 0.55 \\
Extensive & 0.15 & 0.64 & 0.41 & 0.55 \\
Complete & 0.30 & 0.74 & 0.68 & 0.55 \\
\hline
\end{tabular}

\section{Sensitivity Analysis}

The proposed methodology is coping with several uncertain parameters that are essential for the risk appraisal. The uncertainty of the seismic event is expressed in annual rate of exceedance, and the uncertainty of the damage because of the event is expressed in the fragility curve. The construction of fragility curve process aggregates the parameters of several fragility functions which are mainly based on prior studies. For some sub-components, several sources offer different fragility parameters for the sub-component. In those cases, relying on one of the sources will, in some way, effect on the risk curve. Therefore, it is very important to examine the influence range and the sensitivity of the uncertain parameters. In this sensitivity analysis, we examined the marginal cost of the sub-component median.

The following tables presents examination of a change of the median for each damage state of each sub-component $\left(\Delta \theta_{\mathrm{ds}_{\text {sub-component }}}\right)$ and the following change on the medians of the tank farm damage states $\left(\Delta \theta_{\mathrm{ds} \text { oil farm }}\right)$ by value, the value in brackets expresses the percentage change. The first row presents the original values followed by three levels of changes in the median parameter: 50\% reduction, 50\% increase, and 100\% increase.

Table 3 - Summary of the sensitivity analysis by sub-component. The value in brackets expresses the percentage change.

\begin{tabular}{|c|c|c|c|c|c|c|}
\hline & \multirow{2}{*}{\multicolumn{2}{|c|}{ Sub-component }} & \multicolumn{4}{|c|}{ Oil Tank Farm } \\
\hline & & & $0.082(0 \%)$ & $0.128(0 \%)$ & $0.228(0 \%)$ & $0.4(0 \%)$ \\
\hline & $D s_{i}$ & $D s_{i}^{*}$ & $D s_{1}$ & $D s_{2}$ & $D s_{3}$ & $D s_{4}$ \\
\hline \multirow{12}{*}{$\stackrel{\infty}{\stackrel{\infty}{\Xi}}$} & \multirow{3}{*}{$D s_{1}=0.1$} & $0.05(-50 \%)$ & $0.049(-40 \%)$ & $0.128(0 \%)$ & $0.296(30 \%)$ & $0.4(0 \%)$ \\
\hline & & $0.15(50 \%)$ & $0.1(22 \%)$ & $0.128(0 \%)$ & $0.296(30 \%)$ & $0.4(0 \%)$ \\
\hline & & $0.2(100 \%)$ & $0.107(30 \%)$ & $0.128(0 \%)$ & $0.296(30 \%)$ & $0.4(0 \%)$ \\
\hline & \multirow{3}{*}{$D s_{2}=0.15$} & $0.075(-50 \%)$ & $0.061(-26 \%)$ & $0.073(-43 \%)$ & $0.228(0 \%)$ & $0.4(0 \%)$ \\
\hline & & $0.225(50 \%)$ & $0.088(7 \%)$ & $0.162(27 \%)$ & $0.228(0 \%)$ & $0.4(0 \%)$ \\
\hline & & $0.3(100 \%)$ & $0.089(9 \%)$ & $0.183(43 \%)$ & $0.228(0 \%)$ & $0.4(0 \%)$ \\
\hline & \multirow{3}{*}{$D s_{3}=0.3$} & $0.15(-50 \%)$ & $0.074(-10 \%)$ & $0.103(-20 \%)$ & $0.138(-39 \%)$ & $0.4(0 \%)$ \\
\hline & & $0.45(50 \%)$ & $0.083(1 \%)$ & $0.135(5 \%)$ & $0.282(24 \%)$ & $0.4(0 \%)$ \\
\hline & & $0.6(100 \%)$ & $0.083(1 \%)$ & $0.137(7 \%)$ & $0.315(38 \%)$ & $0.4(0 \%)$ \\
\hline & \multirow{3}{*}{$D s_{4}=0.4$} & $0.2(-50 \%)$ & $0.077(-6 \%)$ & $0.111(-13 \%)$ & $0.159(-30 \%)$ & $0.2(-50 \%)$ \\
\hline & & $0.6(50 \%)$ & $0.082(0 \%)$ & $0.132(3 \%)$ & $0.259(14 \%)$ & $0.596(49 \%)$ \\
\hline & & $0.8(100 \%)$ & $0.082(0 \%)$ & $0.133(4 \%)$ & $0.274(20 \%)$ & $0.777(94 \%)$ \\
\hline \multirow{7}{*}{$\frac{n}{\tilde{\Xi}}$} & \multirow{3}{*}{$D s_{1}=0.67$} & $0.335(-50 \%)$ & $0.081(-1 \%)$ & $0.128(0 \%)$ & $0.228(0 \%)$ & $0.4(0 \%)$ \\
\hline & & $1.01(50 \%)$ & $0.082(0 \%)$ & $0.128(0 \%)$ & $0.228(0 \%)$ & $0.4(0 \%)$ \\
\hline & & $1.34(100 \%)$ & $0.082(0 \%)$ & $0.128(0 \%)$ & $0.228(0 \%)$ & $0.4(0 \%)$ \\
\hline & \multirow{3}{*}{$D s_{2}=1.18$} & $0.59(-50 \%)$ & $0.082(0 \%)$ & $0.128(0 \%)$ & $0.228(0 \%)$ & $0.4(0 \%)$ \\
\hline & & 1.77 (50\%) & $0.082(0 \%)$ & $0.128(0 \%)$ & $0.228(0 \%)$ & $0.4(0 \%)$ \\
\hline & & $2.36(100 \%)$ & $0.082(0 \%)$ & $0.128(0 \%)$ & $0.228(0 \%)$ & $0.4(0 \%)$ \\
\hline & $D s_{3}=1.56$ & $0.78(-50 \%)$ & $0.082(0 \%)$ & $0.128(0 \%)$ & $0.227(0 \%)$ & $0.4(0 \%)$ \\
\hline
\end{tabular}




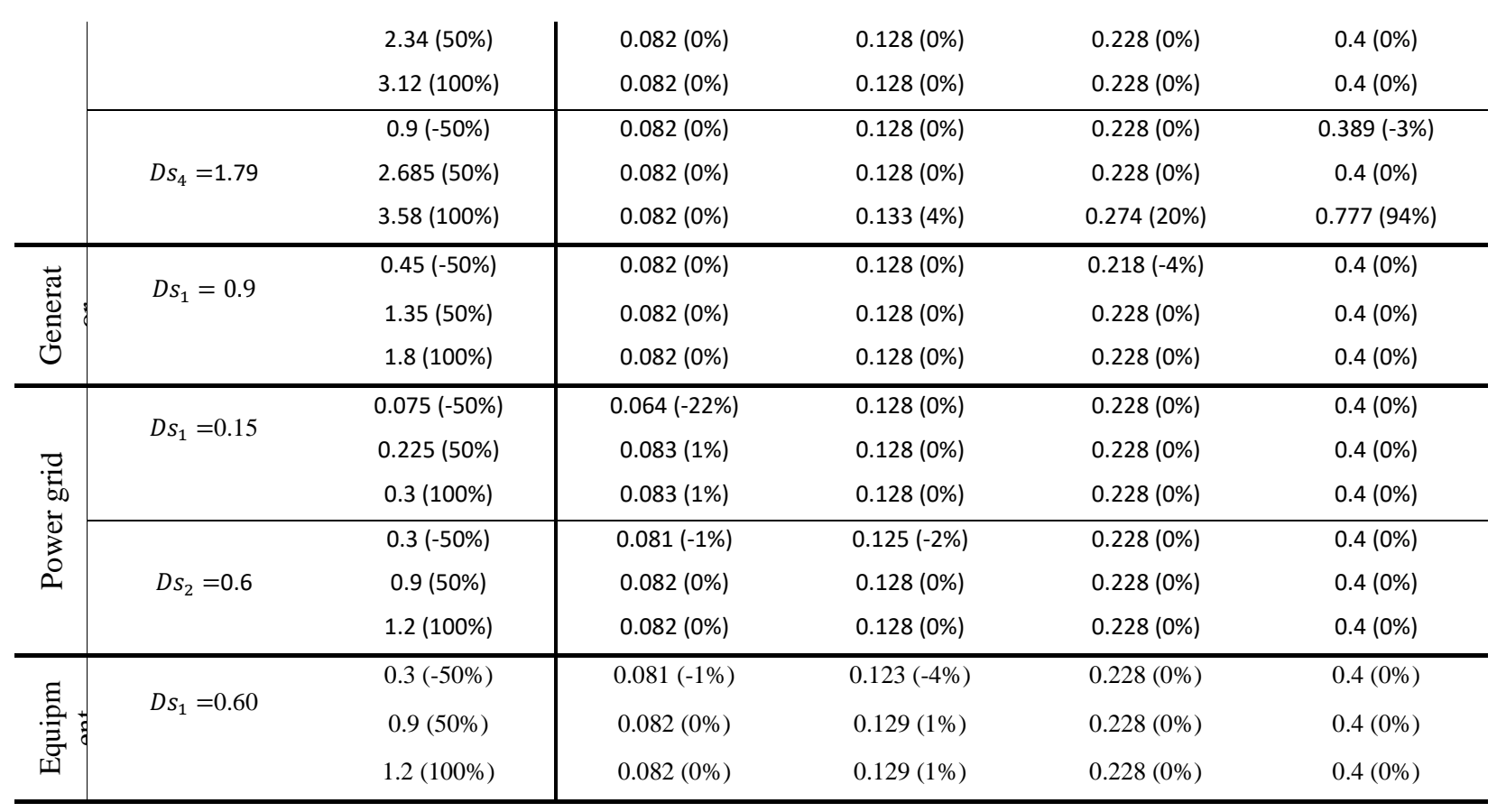

From this examination, we can see that the most significant sub-component in most cases is the building; the fragility curve parameters of the entire system are most sensitive to inaccuracy in the fragility parameters of the building. However, in most cases the change in the farm medians is much smaller than the change in the sub-components median. Moreover, because of the complexity of the system, an inaccuracy of a single parameter will not significantly effect on the risk evaluation of the entire system.

\section{Conclusion}

This paper presents a probabilistic risk appraisal methodology which intended to be used as a decision support tool for decision makers in order to set the priority of mitigation strategies based on the seismic risk expectancy of critical infrastructures.

This paper presents an implementation of this methodology through two case studies: oil tank farm and a pumping plant. The pumping plant case demonstrates the development of a seismic risk function. In this case, the risk expectancy curve reveals that most of the risk is concentrated at the low-moderate peak ground accelerations levels. A possible mitigation strategy was examined, and the subsequent reduction of risk was analysed. It was found that attending the mitigation strategy to the most critical range of ground accelerations can reduce the overall risk expectancy by over $25 \%$. In addition, this paper focuses on the development of an exclusive fragility curve for a unique system, for those cases that the generic fragility curves that are available in the literature are insufficient. The implantation of this approach is presented through the oil tank farm case study; in this illustration, the oil tank farm is composed of five main sub-components: building, storage tanks, power grid, backup generator, and mechanical equipment. Subsequently, based on the fragility parameters of the sub-components and the system damage state definition the fragility curve of the system was yield. A comparison of the results with fragility parameters that are proposed in the literature reveals that the differences between the parameters are most likely due to the differences in the definition of the events that attributed to each damage state. In addition, a preliminary sensitivity analysis of the uncertain parameters (median of the damage states of the various sub-components) was performed; it was found that due to the complexity of the system, an inaccuracy of a single parameter, in most cases, will have insignificant effect on the total risk expectancy of the entire system. 


\section{References}

[1] W. G. Corley et al. The oklahoma city bombing: Summary and recommendations for multihazard mitigation. J. Perform. Constr. Facil. 12(3), pp. 100-112. 1998.

[2] S. M. Baldridge and J. D. Marshall. Performance of structures in the january 2010 MW 7.0 haiti earthquake. Presented at Structures Congress 2011. 2011, . DOI: 10.1061/41171(401)145.

[3] A. Urlainis et al. Damage in critical infrastructures due to natural and man-made extreme Events-A critical review. Procedia Engineering 85pp. 529-535. 2014.

[4] NIBS. HAZUS-MH: Users's manual and technical manuals. report prepared for the federal emergency management agency. National institute of building sciences. Federal Emergency Management Agency (FEMA). Washington, DC. 2004.

[5] ALA, "American lifelines alliance. guideline for assessing the performance of oil and natural gas pipeline systems in natural hazard and human threat events," FEMA-DHS-NIBS, 2005.

[6] P. Gehl et al. "Fragility functions of gas and oil networks," in SYNER-G: Typology Definition and Fragility Functions for Physical Elements at Seismic RiskAnonymous 2014, .

[7] J. W. Baker. An introduction to probabilistic seismic hazard analysis. White Paper Version 2(1), pp. 79. 2013.

[8] N. A. Abrahamson. Abrahamson \& silva NGA ground motion relations for the geometric mean horizontal component of peak and spectral ground motion parameters. PEER Report Draft V2, Pacific Earthquake Engineering Research Center, Berkeley, CA pp. 380.2007.

[9] N. Abrahamson and W. Silva. Summary of the abrahamson \& silva NGA ground-motion relations. Earthquake Spectra 24(1), pp. 67-97. 2008.

[10] M. J. O'Rourke and P. So. Seismic fragility curves for on-grade steel tanks. Earthquake Spectra 16(4), pp. 801-815. 2000.

[11] M. Razzaghi and S. Eshghi. Development of analytical fragility curves for cylindrical steel oil tanks. Presented at Proccedings of the $14 \mathrm{Th}$ World Conference on Earthquake Engineering. 2008, .

[12] ALA. American Lifelines Alliance. Seismic Fragility Formulations for Water Systems 2001.

[13] K. Porter, R. Kennedy and R. Bachman. Creating fragility functions for performance-based earthquake engineering. Earthquake Spectra 23(2), pp. 471-489. 2007.

[14] K. Porter, R. Hamburger and R. Kennedy. Practical development and application of fragility functions. Presented at Proc. of SEI Structures Congress, Long Beach CA, America. 2007, .

[15] J. W. Baker. Efficient analytical fragility function fitting using dynamic structural analysis. Earthquake Spectra 31(1), pp. 579-599. 2015.

[16] A. Urlainis, I. M. Shohet and R. Levy. Probabilistic risk assessment of oil and gas infrastructures for seismic extreme events. Procedia Engineering 123pp. 590-598. 2015.

[17] M. O'Rourke. Analytical fragility relation for buried segmented pipe. Proceedings of the TCLEE 2009: Lifeline Earthquake Engineering in a Multihazard Environment pp. 771-780. 2009.

[18] A. Klar et al. Spectral acceleration maps for use in SI 413 amendment no.5. The Geophysical Institute of Israel. Israel. 2011.

[19] K. W. Campbell and Y. Bozorgnia. NGA ground motion model for the geometric mean horizontal component of PGA, PGV, PGD and 5\% damped linear elastic response spectra for periods ranging from 0.01 to 10 s. Earthquake Spectra 24(1), pp. 139-171. 2008.

[20] FEMA, "Seismic performance assessment of buildings - FEMA P-58," FEMA, Washington, D.C., 2012. 